\title{
Advances in Functional Inorganic Materials Prepared by Wet Chemical Methods
}

\author{
Aleksej Zarkov $^{1, * \mathbb{D}}$, Aivaras Kareiva ${ }^{1}(\mathbb{D})$ and Loreta Tamasauskaite-Tamasiunaite ${ }^{2} \mathbb{D}$ \\ 1 Institute of Chemistry, Vilnius University, Naugarduko 24, LT-03225 Vilnius, Lithuania; \\ aivaras.kareiva@chgf.vu.lt \\ 2 Center for Physical Sciences and Technology, Sauletekio Ave. 3, LT-10257 Vilnius, Lithuania; \\ loreta.tamasauskaite@ftmc.lt \\ * Correspondence: aleksej.zarkov@chf.vu.lt
}

Citation: Zarkov, A.; Kareiva, A.; Tamasauskaite-Tamasiunaite, L. Advances in Functional Inorganic Materials Prepared by Wet Chemical Methods. Crystals 2021, 11, 943. https://doi.org/10.3390/cryst11080943

Received: 4 August 2021

Accepted: 12 August 2021

Published: 13 August 2021

Publisher's Note: MDPI stays neutral with regard to jurisdictional claims in published maps and institutional affiliations.

Copyright: (C) 2021 by the authors Licensee MDPI, Basel, Switzerland. This article is an open access article distributed under the terms and conditions of the Creative Commons Attribution (CC BY) license (https:// creativecommons.org/licenses/by/ $4.0 /)$
Functional inorganic materials are an indispensable part of innovative technologies, which are essential to the development of many fields of industry. The use of new materials, nanostructures, or multicomponent composites with specific chemical or physical properties promotes technological progress in electronics, optoelectronics, catalysis, biomedicine, and many other areas that are concerned with plenty of aspects of human life. Due to the broad and diverse range of the potential applications of functional inorganic materials, the development of superior synthesis pathways, reliable characterization, and a deep understanding of the structure-property relationships in materials, are rightfully considered to be fundamentally important scientific issues. Only synergetic efforts of scientists dealing with the synthesis, functionalization, and characterization of materials will lead to the development of future technologies. The Special Issue on "Advances in Functional Inorganic Materials Prepared by Wet Chemical Methods" covers a broad range of preparation routes, characterization, and the application of functional inorganic materials, as well as hybrid materials that are important in the fields of electronics, optics, biomedicine, and others.

The sol-gel method is a simple, time- and cost-effective synthetic approach providing high homogeneity and stoichiometry control of the products. These reasons make it highly suitable for the preparation of mixed-metal oxide materials and different solid solutions. For instance, Grazenaite et al. [1] employed an aqueous sol-gel method for the preparation of Ga-substituted cobalt-chromium spinels as ceramic pigments. The ion substitution resulted in significant color tuning. This demonstrated that the full substitution of $\mathrm{Cr}^{3+}$ by $\mathrm{Ga}^{3+}$ ions led to the formation of light blue powders, which yielded a violet blue color for the corresponding ceramic glaze. Karoblis et al. [2] utilized the sol-gel method for the synthesis of $(1-\mathrm{x}) \mathrm{SrTiO}_{3}-\mathrm{xBiMnO}_{3}$ solid solutions in order to obtain new multiferroic material. The results indicated that single-phase perovskites with a cubic structure can only be synthesized up to $\mathrm{x}=0.3$. A higher $\mathrm{BiMnO}_{3}$ content led to the formation of a negligible amount of the neighboring $\mathrm{Mn}_{3} \mathrm{O}_{4}$ phase. Nevertheless, some compositional trends were observed in this range. The grain size increased drastically with an increase of $\mathrm{BiMnO}_{3}$, moreover, the gradual increase of the $\mathrm{BiMnO}_{3}$ content resulted in noticeably higher magnetization values. Finally, using the sol-gel method, Inkrataite et al. [3] prepared cerium and chromium co-doped gadolinium-aluminum-gallium garnet (GAGG, $\mathrm{Gd}_{3} \mathrm{Al}_{2} \mathrm{Ga}_{3} \mathrm{O}_{12}$ ). The remarkable feature of this study is that an exceptionally intense emission in the near-infrared region (NIR) was achieved with an extremely low doping level. The chromium content in the obtained materials reached only $15 \mathrm{ppm}$. Another example of optical materials was provided by Buyer et al. [4]. The authors were able to synthesize $\mathrm{Eu}^{3+}$-substituted $\mathrm{NaY}_{[}\left[\mathrm{SO}_{4}\right]_{2} \mathrm{H}_{2} \mathrm{O}$ under hydrothermal conditions. The anhydrated version of this material $\left(\mathrm{NaY}\left[\mathrm{SO}_{4}\right]_{2}\right)$ was obtained by the post-annealing of as-prepared species. The structural and thermal properties of the synthesized compound were investigated in detail. Both compounds exhibited a strong emission in red region. 
Wet chemical methods allow not only crystalline to synthesize, but also amorphous materials, which can be very attractive for medical applications. A hydrothermal approach was employed by Anh Tuan et al. [5] for the preparation of bioactive glass $58 \mathrm{SiO}_{2}-33 \mathrm{CaO}-$ $9 \mathrm{P}_{2} \mathrm{O}_{5}$. The proposed synthetic approach avoided the use of harmful acid catalysts and was confirmed as one of the ideal methods for the preparation of ternary bioactive glass. For specific medical applications more complex hybrid organic-inorganic structures can be used. For example, the successful preparation of the biocompatible nanohybrid of ciprofloxacin-Ag/ $\mathrm{TiO}_{2} /$ chitosan was demonstrated by Zafar et al. [6]. The obtained nanaheterostructures were shown to be effective against mastitis causing E. coli.

Titanium dioxide, besides being used in heterostructures for biomedical applications, is a very technologically important material, which can be utilized for a broad range of applications. In this light, simple and cost-effective methods for the synthesis of $\mathrm{TiO}_{2}$ are highly desirable. Serga et al. [7] demonstrated for the first time the possibilities of the extraction-pyrolytic method (EPM) for the production of nanocrystalline $\mathrm{TiO}_{2}$ powders. It was observed that the EPM permitted the production of both monophase (anatase or rutile polymorph) and biphase (mixed anatase-rutile polymorphs) nanocrystalline $\mathrm{TiO}_{2}$. The influence of poly(titanium oxide) obtained using the sol-gel method on the viscoelastic and thermophysical properties of interpenetrating polymer networks (IPNs) based on crosslinked polyurethane (PU) and poly(hydroxyethyl methacrylate) (PHEMA), was studied by Tsebriienko and Popov [8]. It was found that an increase in poly(titanium oxide) content led to a decrease in the intensity of the relaxation maximum for PHEMA phase and an increase in the effective crosslinking density due to the partial grafting of the inorganic component to acrylate.

Carbon-supported $\mathrm{MnO}_{2}$ nanocomposites for the application of supercapacitors were fabricated by Jablonskiene et al. [9] using the microwave-assisted heating method. For comparison, the nanocomposites were synthesized by one-step and two-step approaches. The high specific capacitance of $980.7 \mathrm{~F} \mathrm{~g}^{-1}$ was achieved from cyclic voltammetry measurements, whereas the specific capacitance of $949.3 \mathrm{~F} \mathrm{~g}^{-1}$ at $1 \mathrm{~A} \mathrm{~g}^{-1}$ was obtained from a galvanostatic charge/discharge test. The specific capacitance retention was $93 \%$ after 100 cycles at $20 \mathrm{~A} \mathrm{~g}^{-1}$, indicating good electrochemical stability.

Zeng et al. [10] utilized hydrothermally synthesized $\mathrm{ZnO}$ nanowires for the fabrication of $2 \mathrm{D} \mathrm{Bi}_{2} \mathrm{Se}_{3} / \mathrm{ZnO}$ heterojunction, which was employed for the broadband photodetection. The fabricated heterojunction device demonstrated not only an enhanced photoresponsivity of $0.15 \mathrm{~A} / \mathrm{W}$ at $377 \mathrm{~nm}$, which was three times higher than that of bare $\mathrm{ZnO}$ nanowire $(0.046 \mathrm{~A} / \mathrm{W})$, but also achieved a broadband photoresponse from UV to near-infrared region was achieved.

The present Special Issue on "Advances in Functional Inorganic Materials Prepared by Wet Chemical Methods" demonstrates the versatility of wet chemical methods for the preparation of functional materials for a broad range of applications. It can be considered as a status report reviewing the progress that has been achieved in the processing of inorganic materials.

Author Contributions: Conceptualization, A.Z., A.K. and L.T.-T.; writing-original draft preparation, A.Z., A.K. and L.T.-T.; writing-review and editing, A.Z., A.K. and L.T.-T.; funding acquisition, A.Z. and A.K. All authors have read and agreed to the published version of the manuscript.

Funding: This project has received funding from European Social Fund (project No. 09.3.3-LMT-K712-19-0069) under grant agreement with the Research Council of Lithuania (LMTLT).

Conflicts of Interest: The authors declare no conflict of interest.

\section{References}

1. Grazenaite, E.; Garskaite, E.; Stankeviciute, Z.; Raudonyte-Svirbutaviciene, E.; Zarkov, A.; Kareiva, A. Ga-substituted cobaltchromium spinels as ceramic pigments produced by sol-gel synthesis. Crystals 2020, 10, 1078. [CrossRef]

2. Karoblis, D.; Diliautas, R.; Raudonyte-Svirbutaviciene, E.; Mazeika, K.; Baltrunas, D.; Beganskiene, A.; Zarkov, A.; Kareiva, A. The Synthesis and characterization of sol-gel-derived $\mathrm{SrTiO}_{3}-\mathrm{BiMnO}_{3}$ solid solutions. Crystals 2020, 10, 1125. [CrossRef] 
3. Inkrataite, G.; Laurinavicius, G.; Enseling, D.; Zarkov, A.; Jüstel, T.; Skaudzius, R. Characterization of GAGG doped with extremely low levels of chromium and exhibiting exceptional intensity of emission in NIR region. Crystals 2021, 11, 673. [CrossRef]

4. Buyer, C.; Enseling, D.; Jüstel, T.; Schleid, T. Hydrothermal synthesis, crystal structure, and spectroscopic properties of pure and $\mathrm{Eu}^{3+}$-doped NaY $\left[\mathrm{SO}_{4}\right]_{2} \mathrm{H} 2 \mathrm{O}$ and Its Anhydrate NaY $\left[\mathrm{SO}_{4}\right]_{2}$. Crystals 2021, 11, 575. [CrossRef]

5. Anh Tuan, T.; Guseva, E.V.; Anh Tien, N.; Tan Dat, H.; Vuong, B.X. Simple and acid-free hydrothermal synthesis of bioactive glass $58 \mathrm{SiO}_{2}-33 \mathrm{CaO}-9 \mathrm{P}_{2} \mathrm{O}_{5}(\mathrm{wt} \%)$. Crystals 2021, 11, 283. [CrossRef]

6. Zafar, N.; Uzair, B.; Niazi, M.B.K.; Samin, G.; Bano, A.; Jamil, N.; Un-Nisa, W.; Sajjad, S.; Menaa, F. Synthesis and characterization of potent and safe ciprofloxacin-loaded $\mathrm{Ag} / \mathrm{TiO}_{2} / \mathrm{CS}$ nanohybrid against mastitis causing E. coli. Crystals 2021, 11, 319. [CrossRef]

7. Serga, V.; Burve, R.; Krumina, A.; Romanova, M.; Kotomin, E.A.; Popov, A.I. Extraction-pyrolytic method for TiO 2 polymorphs production. Crystals 2021, 11, 431. [CrossRef]

8. Tsebriienko, T.; Popov, A.I. Effect of poly(titanium oxide) on the viscoelastic and thermophysical properties of interpenetrating polymer networks. Crystals 2021, 11, 794. [CrossRef]

9. Jablonskiene, J.; Simkunaite, D.; Vaiciuniene, J.; Stalnionis, G.; Drabavicius, A.; Jasulaitiene, V.; Pakstas, V.; TamasauskaiteTamasiunaite, L.; Norkus, E. Synthesis of carbon-supported $\mathrm{mno}_{2}$ nanocomposites for supercapacitors application. Crystals 2021, 11, 784. [CrossRef]

10. Zeng, Z.; Wang, D.; Wang, J.; Jiao, S.; Liu, D.; Zhang, B.; Zhao, C.; Liu, Y.; Liu, Y.; Xu, Z.; et al. Broadband detection based on 2D $\mathrm{Bi}_{2} \mathrm{Se}_{3} / \mathrm{ZnO}$ nanowire heterojunction. Crystals 2021, 11, 169. [CrossRef] 